\title{
Daddy, Mommy, and Money: The Association Between Parental Materialism on Parent-Child Relationship Quality
}

\author{
David B. Allsop \\ Dalhousie University \\ Chen-Yun Wang \\ Brigham Young University - Provo \\ Jeffrey P. Dew \\ Brigham Young University - Provo, jeff_dew@byu.edu \\ Erin K. Holmes \\ Brigham Young University - Provo \\ E. Jeffrey Hill

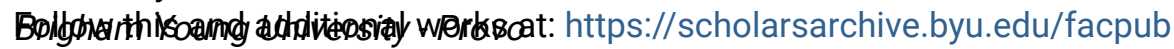 \\ Part of the Other Social and Behavioral Sciences Commons
}

See next page for additional authors

Original Publication Citation

Allsop, D. B.*, Wang, C.-Y.*, Dew, J. P., Holmes, E. K., Hill, E. J., \& Leavitt, C. E. (2020). Daddy, mommy, and money: The association between parental materialism on parent-child relationship quality. Journal of Family and Economic Issues.

\section{BYU ScholarsArchive Citation}

Allsop, David B.; Wang, Chen-Yun; Dew, Jeffrey P.; Holmes, Erin K.; Hill, E. Jeffrey; and Leavitt, Chelom E., "Daddy, Mommy, and Money: The Association Between Parental Materialism on Parent-Child Relationship Quality" (2020). Faculty Publications. 4546.

https://scholarsarchive.byu.edu/facpub/4546

This Peer-Reviewed Article is brought to you for free and open access by BYU ScholarsArchive. It has been accepted for inclusion in Faculty Publications by an authorized administrator of BYU ScholarsArchive. For more information, please contact ellen_amatangelo@byu.edu. 


\section{Authors}

David B. Allsop, Chen-Yun Wang, Jeffrey P. Dew, Erin K. Holmes, E. Jeffrey Hill, and Chelom E. Leavitt 


\title{
Daddy, Mommy, and Money: The Association Between Parental Materialism on Parent-Child Relationship Quality
}

\author{
David B. Allsop ${ }^{1}$ D $\cdot$ Chen-Yun Wang ${ }^{2}$. Jeffrey P. Dew ${ }^{2}$ Erin K. Holmes ${ }^{2} \cdot$ E. Jeffrey Hill ${ }^{2} \cdot$ Chelom E. Leavitt $^{2}$
}

(c) Springer Science+Business Media, LLC, part of Springer Nature 2020

\begin{abstract}
This study examined the longitudinal relationships among materialism, parent-child relationship quality, and psychological control for fathers and mothers. Data came from 254 heterosexual couples participating in the Flourishing Families Project, a 10-year longitudinal study of inner family life. We found that the association of parents' materialism at T1 and parent-child relationship at $\mathrm{T} 2$ differed by gender. In harmony with our hypothesis, fathers' materialism at $\mathrm{T} 1$ significantly predicted a decrease in father-child relationship quality at T2. Contrary to our hypothesis, mothers' materialism at T1 was not significantly associated with mother-child relationship quality at T2. Parental psychological control was negatively related to both father-child and motherchild relationship quality but did not serve as a moderator in the relationship between materialism and parent-child relationships. That materialism appears to be detrimental to father-child relationship quality but not detract from mother-child relationship quality is thought provoking. We propose several possible explanations for these disparate findings, including a possible link between materialism and empowerment for women (but not men), and that materialism for women (but not men) may be associated with goods purchased for the benefit of the family rather than the individual. We provide suggestions for future research based on these findings.
\end{abstract}

Keywords Materialism $\cdot$ Parent child relations $\cdot$ Parenting $\cdot$ Parent psychological control $\cdot$ Coercion $\cdot$ Adolescent development

This is one of several papers published together in Journal of Family and Economic Issues on the "Special Issue on Couples, Families, and Finances".

David B. Allsop

david.allsop@dal.ca

Chen-Yun Wang

daisysmile1992@gmail.com

Jeffrey P. Dew

jeff_dew@byu.edu

Erin K. Holmes

erin_holmes@byu.edu

E. Jeffrey Hill

jeff_dew@byu.edu

Chelom E. Leavitt

chelom_leavitt@byu.edu

1 Dalhousie University, Halifax, Canada

2 Brigham Young University, Provo, USA

\section{Introduction}

Scholars have investigated materialism-the importance individuals put on extrinsic possessions when evaluating their self-concept and success (Kasser and Ryan 1993)in a variety of contexts, including among individuals (Chakraborty and Chatterjee 2015), peers (Jiang et al. 2015), and spouses (Carroll et al. 2011; Dean et al. 2007). One area that has received little attention is the parent-child domain. Some research has examined how parents influence levels of materialism in children (Flouri 2004) or how parental involvement or stress relates to parental levels of materialism (Flouri 2007). However, to our knowledge, no major study has examined whether parental materialism is associated with the parent-child bond.

Parents-seeking to balance relationships with their children and material goals - and practitioners-such as financial therapists helping clients manage attitudes toward material goods in the context of their family relationships-may be more effective if they understand the association between parental materialism and parent-child relationship quality. 
Overall, cross-sectional studies indicate that materialism is negatively related to a variety of outcomes including life satisfaction (Ryan and Dziurawiec 2001), emotional well-being (Chakraborty and Chatterjee 2015), psychological health (Flouri 2007), marital satisfaction (Carroll et al. 2011; Dean et al. 2007) and parenting (Flouri 2007). By extension, and in line with the Incompatibility of Materialism and Children model ( $\mathrm{Li}$ et al. 2011), it is possible that the link between parental materialism and the bond of parents and children follows this negative trend (Li et al. 2011) and that this trend may persist longitudinally.

We test this proposition. We first discuss the theory grounding our investigation and review literature about materialism and relationships. Then, we review literature supporting the importance of psychological control in our investigation.

\section{Self Determination Theory and Materialism}

Ryan and Deci's (2002) self-determination theory (SDT) is a useful framework for conceptualizing the link between parental materialism and parent-child relationships. SDT addresses how motivations affect individual psychological needs. SDT asserts that individuals have three crucial psychological needs: relatedness, competence, and autonomy. Relatedness refers to an orientation toward forming strong and stable interpersonal bonds, competence refers to the propensity to experience challenge and mastery in one's activity, and autonomy refers to self-initiation and volition of one's behavior (Deci and Ryan 1980; Ryan and Deci 2002).

SDT also suggests that intrinsic and extrinsic motivations of individuals affect individual behavior and the three basic psychological needs. Intrinsic motivations refer to the focus of people's innate psychological needs or inherent growth tendencies and the mechanism of inward motivation of their behaviors, such as interests and enjoyment. In contrast, extrinsic motivations focus on outward-oriented values, such as making a good impression on others by their physical looks, personal possession, or financial achievements. SDT suggests that intrinsic motivation contributes to the fulfillment of the three psychological needs but extrinsic motivation detracts from realizing them (Deci and Ryan 2000). Further, researchers have found that people who are externally motivated are less likely to connect with others in a close, authentic and interpersonally trusting way (Kasser and Ryan 2001; see also Richins and Dawson 1992). Of note, studies most often point to motivations as predictors of needs but certainly bidirectional relationships between needs and motivations are possible. In the current study we focus on motivations as predictors of needs.

Conceptualized through the framework of SDT, the generally negative influence of materialism can be better understood. We acknowledge that a variety of motivations, both intrinsic and extrinsic, can underpin materialistic behavior (Kasser and Ryan 1993, 1996). That is, individuals may focus on acquiring possessions to reach a desired standard of living, status, or level of happiness (Richins 2004; Richins and Dawson 1992), for financial security (Kasser 2002), to enhance life satisfaction (Kashdan and Breen 2007; Belk 1984), or meet goals in other life domains (Roberts and Clement 2007; Easterlin and Crimmins 1991). Because of this, it is possible that materialism could be linked with both positive and negative outcomes and some studies have found this to be the case (Easterlin and Crimmins 1991; Sirgy et al. 2013; Shrum et al. 2014).

However, since materialistic individuals often use social comparison as a basis to evaluate their lives (Sirgy 1998), it may be difficult to not be externally motivated when being materialistic. This might more regularly link materialism to negative relationship outcomes. This could be due to the tendency of materialistic individuals to place more value on extrinsic possessions than on intrinsic needs (such as personal relationships and affiliations with other people) (Richins and Dawson 1992). It could also be due to the tendency of materialistic individuals to disregard relational conflict arising from highly valuing money and possessions (Promislo et al. 2010).

Whatever the explanation, materialism is often associated with negative relational outcomes. Generally, these include poorer interpersonal relationships and lower perceived social support (Burroughs and Rindfleisch 2002; Christopher and Schlenker 2004). Specific to marital relationships, these include less other-centeredness, less effective communication, and more negative interactions (Carroll et al. 2011). In terms of parenting, fathers' materialism is linked with higher inter-parental conflict and parenting stress (Flouri 2007). Across contexts, it is clear that materialism is linked with less healthy relationships. In light of previous research, we offer the following hypothesis:

Hypothesis 1 Parental materialism will be negatively associated with parent-child relationship quality.

\section{The Moderating Effect of Psychological Control}

One important construct that may moderate the link between parental materialism and the connection of parent to child is parental psychological control. The presence of parental psychological control- "parents' attempt to control the child's activities in ways that negatively affect the child's psychological world and thereby undermines the child's psychological development" (Smetana and Daddis 2002, p. 563)-may exacerbate the negative influence of parental 
materialism on parent-child bonds. Parents who are psychologically controlling may coerce children into fulfilling their extrinsically motivated materialistic goals. Examples of psychological control include, but are not limited to, constraining verbal expression, invalidating feelings, and inducing guilt. If unhealthy external materialistic motivation is forced into the parent-child relationship, the bond between child and parent may diminish.

For example, a materialistic parent may coerce a child into dressing in clothing which is expensive and which the parent considers fashionable (even if the child does not) in order for the parent to satisfy materialistic goals. The child coerced by the materialistic parent to dress in certain clothes and styles might then have a poorer relationship with their parent (relatedness), less confidence in their self-image (competence), and worse self-efficacy (autonomy).

Putting it all together, parent-child relationships may be harmed separately by materialism (Burroughs and Rindfleisch 2002; Christopher and Schlenker 2004) and psychological control (Smetana and Daddis 2002) but may especially be harmed by the combination of these constructs. Subsequently, we offer the following hypotheses:

Hypothesis 2 Parental psychological control will be negatively associated with parent-child relationship quality.

Hypothesis 3 Parental psychological control will moderate the association between parental materialism and parentchild relationship quality.

\section{Methods}

\section{Participants and Procedure}

To test our hypotheses, we utilized data from 254 families composed of mothers, fathers and a selected child. Data came from the Flourishing Families Project (FFP; Day et al. 2016), a longitudinal study of inner family life. Every year, for ten years, individuals completed a survey, and, in the first seven years of the project, families completed various tasks that were recorded and later coded. The FFP recruited participants from a large northwestern city in the United States using a randomized cluster design primarily based on a marketing telephone directory. It also oversampled families of lower-socioeconomic status using flyers. Across the ten waves, over $90 \%$ of families who began the study were retained through wave ten. Time one data, including sample demographics/controls, came from wave four of the FFP and time two data came from wave five. The exception to this was racial demographics/controls that came from wave one. We used data from waves four and five based on the availability of our constructs of interest. Parents were given $\$ 100$ and adolescents were given $\$ 50$ for their participation.

Mothers' mean age was $46.36(S D=5.41)$, fathers mean age was $48.14(S D=5.90)$, and children's mean age was $14.24(S D=.98)$. On average, mothers and fathers had been married 20.79 years $(S D=5.16)$. The sample was relatively affluent with the mean combined household income being $\$ 126,964(S D=\$ 100,125)$. $49 \%$ of children were female and $51 \%$ of children were male. Most children were Caucasian $(80 \%)$ with a subset being Black/African American (3\%), Hispanic (2\%), Asian American (4\%), and multiethnic (11\%).

\section{Measures}

\section{Materialism}

An initial 12 item scale assessed materialism with six items from Richins and Dawson (1992) and six from Carroll (2004). We conducted a factor analysis on the 12 items and, after removing four items that were poorly loading or crossloading, the remaining eight items loaded onto two factors (Table 1). The two-factor solution was appropriate based on results from (a) a scree plot and (b) rotated factor loadings from principal axis factoring (with Promax rotation and Kaiser normalization). The first factor seemed to represent a desire to provide goods for family members. As this factor did not align with our theoretical lens (SDT), in that it did not represent external motivation, it was subsequently not utilized in the current study. Alternatively, the second factor, in our view, represented obvious social comparison and external motivation for obtaining material goods, and thus we utilized the four items (items 5-8) from this factor. This four-item scale aligned with the tenet in SDT that external motivation is harmful to relationships. The second factor included items such as "I like to own things that impress people" that were scored on a five-point scale ranging from one (strongly disagree) to five (strongly agree) (father $\alpha=.77$, mother $\alpha=.77$ ). Father and mother reports of materialism were modeled as separate latent constructs with manifest variables as indicators.

\section{Parental Psychological Control}

The child in each family responded to Barber's (1996) eightitem measure of parental psychological control for both their father and mother. The children could respond to these questions by indicating their agreement with statements such as "My parent is less friendly with me if I do not see things her/ his way," on a five-point scale ranging from one (never) to five (always). Internal consistency across all eight items per parent was good (child report of father $\alpha=.87$; child report of mother $\alpha=.86$ ). We combined reports of both parents 
Table 1 Rotated factor loading structure matrix for materialism measure

\begin{tabular}{|c|c|c|c|c|c|}
\hline \multirow[t]{3}{*}{$\#$} & \multirow[t]{3}{*}{ Item } & \multirow{2}{*}{\multicolumn{2}{|c|}{$\frac{\text { Father }}{\text { Factors }}$}} & \multirow{2}{*}{\multicolumn{2}{|c|}{$\frac{\text { Mother }}{\text { Factors }}$}} \\
\hline & & & & & \\
\hline & & 1 & 2 & 1 & 2 \\
\hline 1. & Having a home or condo in a nice neighborhood is a priority for me & .59 & .09 & .58 & .30 \\
\hline 2. & I want my kids to dress in fashionable clothes & .63 & .13 & .70 & .48 \\
\hline 3. & I want my family to have the finer things in life & .83 & .24 & .78 & .35 \\
\hline 4. & Having a high salary is an essential part of the lifestyle I want to live & .76 & .19 & .75 & .32 \\
\hline 5. & I admire people who own expensive homes, cars, and clothes & .14 & .69 & .35 & .71 \\
\hline 6. & $\begin{array}{l}\text { Some of the most important achievements in life include acquiring } \\
\text { material possessions }\end{array}$ & .22 & .75 & .40 & .73 \\
\hline 7. & The things I own say a lot about how well I'm doing in life & .12 & .65 & .29 & .65 \\
\hline 8. & I like to own things that impress people & .14 & .64 & .31 & .64 \\
\hline
\end{tabular}

Extraction method principal axis factoring; Rotation method Promax with Kaiser normalization; The factor items are best associated with is indicated in bold; The second factor, items $5-8$, represent external motivation for obtaining material items into one variable due to the high correlation between child assessments of father and mother psychological control $(r=.83, p<.01)$. This was done by constructing a secondorder, latent psychological control variable composed of two other latent variables - a latent father psychological control variable and a latent mother psychological control, each with their own observed indicators. We refer to this variable as combined parental psychological control.

\section{Parent-Child Relationship Quality}

Parent-child relationship quality was assessed by a trained coder using a multistage process. Each parent and child performed tasks together as part of the data collection process in addition to taking the survey. These tasks included discussion, problem solving, and teaching tasks between parents and children that were video recorded. Trained coders then coded the videos using the following steps: (1) they watched the entire video of interactions through once without coding; (2) they watched again (randomly choosing a parent to focus on) coding and timestamping various interaction patterns such as warmth, prosocial behavior, antisocial behavior hostility and several other patterns; (3) they watched again verifying timestamps and codes for previous parent and give scores on interaction patterns; (4) they repeated steps two and three for the other parent; (5) they provided scores on various observational scales (e.g., warmth, communication, hostility, antisocial behavior); (6) they provided a global score of the relationship quality between each parent and the child (i.e., a score for the mother-child relationship and a score for the father-child relationship) keeping in mind all previous scales coded; previous scales were kept in mind by the coder when giving this score, but no mathematical procedure (e.g., averaging) was conducted from previous scales to generate these global scores; (7) parent-child interactions were double coded in some instances by another coder to ensure reliability in the coding process (average inter-rater reliability across all coded interactions was .90). Scores for parent-child relationship quality ranged from one (poor) to nine (good). (Melby et al. 1998).

\section{Analysis}

We conducted univariate and bivariate analysis using SPSS (Version 25, IBM Corp. 2017) to better understand the data (Table 2). Regarding univariate analysis, a salient finding was that both father and mother materialism reports were in the lower range of the scale (approximately 2 out of a 5-point scale). Univariate analysis also suggested that, on average, parents in the sample used psychological control infrequently and were, on average, rated by observers as having good quality relationships with their children. Also, we note that both father and mother materialism and psychological control have significant negative correlations with mother-child and father-child relationship quality.

Next, we made preparations to run our structural models in Mplus (Version 8; Muthén and Muthén 1998-2017). Standardized factor loadings for all latent variable indicators were .44 or greater. To test the moderating effect of psychological control, we created latent interaction terms in Mplus between individual parent materialism reports and the second-order, combined parental psychological control variable. In total, two interaction variables were created. 
Table 2 Univariate and bivariate statistics of measures

\begin{tabular}{|c|c|c|c|c|c|c|c|c|c|c|c|c|}
\hline & Variable & $\bar{X}$ & $\sigma$ & Range $^{\mathrm{a}}$ & 1 & 2 & 3 & 4 & 5 & 6 & 7 & 8 \\
\hline 1. & F. materialism & 1.96 & .69 & $1-4.5(1-5)$ & - & & & & & & & \\
\hline 2. & M. materialism & 1.88 & .67 & $1-4(1-5)$ & $.22 * *$ & - & & & & & & \\
\hline 3. & F. psychological control & 1.82 & .69 & $1-4.9(1-5)$ & $.12 *$ & .07 & - & & & & & \\
\hline 4. & M. psychological control & 1.92 & .73 & $1-4.5(1-5)$ & .09 & .08 & $.83 * *$ & - & & & & \\
\hline 5. & F. child rel. quality (T1) & 5.01 & .89 & $1-7(1-9)$ & -.07 & -.11 & $-.22 * *$ & $-.15^{*}$ & - & & & \\
\hline 6. & M. child rel. quality (T1) & 5.09 & 1.06 & $1-7(1-9)$ & -.04 & -.08 & -.11 & $-.17 * *$ & $.41 * *$ & - & & \\
\hline 7. & F. child rel. quality (T2) & 4.97 & 1.00 & $1-7(1-9)$ & $-.19 * *$ & $-.13^{*}$ & $-.28 * *$ & $-.21 * *$ & $.27 * *$ & $.16^{*}$ & - & \\
\hline 8. & M. child rel. quality (T2) & 4.98 & 1.20 & $1-7(1-9)$ & $-.15^{*}$ & .01 & $-.19 * *$ & $-.21 * *$ & .09 & $.28 * *$ & $.47 * *$ & - \\
\hline
\end{tabular}

$* p<.05 . * * p<.01$

actual range of data listed without parenthesis and possible range from questionnaire listed with parenthesis; "F" short for "father, "M" short for "mother", and "Rel" for "Relationship

We ran a model without the interactions included (Model 1) and one with the interactions (Model 2). Both models controlled for father-child relationship quality and mother-child relationship quality at time one. We used maximum likelihood estimation in Model 1 and, to model the latent variable interaction, maximum-likelihood-robust estimation in Model 2. Over $90 \%$ of data was present for each variable utilized in the analysis. In the proceeding section, coefficients are presented in text for the second model as it includes the interaction model. However, both models are presented in Table 3.

\section{Results}

\section{Hypothesis 1: Parental Materialism and Parent- Child Relationship Quality}

We partially confirmed Hypothesis 1, that parental materialism will be negatively associated with parent-child relationship quality. Father materialism significantly predicted a decline in father-child relationship quality over

Table 3 Standardized results of structural model predicting father-child and mother-child relationship quality

\begin{tabular}{|c|c|c|c|c|}
\hline \multirow[t]{2}{*}{ Time 1 predictor } & \multicolumn{2}{|l|}{ Model 1} & \multicolumn{2}{|l|}{ Model 2} \\
\hline & $\begin{array}{l}\text { T2 father-child } \\
\text { relationship } \\
\text { quality }\end{array}$ & $\begin{array}{l}\mathrm{T} 2 \text { mother-child } \\
\text { relationship } \\
\text { quality }\end{array}$ & $\begin{array}{l}\text { T2 father-child } \\
\text { relationship } \\
\text { quality }\end{array}$ & $\begin{array}{l}\text { T2 mother-child } \\
\text { relationship } \\
\text { quality }\end{array}$ \\
\hline Father materialism & $-.17^{*}$ & -.13 & $-.19 *$ & -.15 \\
\hline Mother materialism & -.05 & .08 & -.04 & .08 \\
\hline Combined parental psychological control & $-.21 * *$ & $-.18^{*}$ & $-.21 * *$ & $-.19 * *$ \\
\hline Father materialism $\times$ combined parental psychological control & - & - & -.13 & -.04 \\
\hline Mother materialism $\times$ combined parental psychological control & - & - & .06 & .07 \\
\hline \multicolumn{5}{|l|}{ Controls } \\
\hline T1 child relationship with father & $.23 * * *$ & - & $.22 * * *$ & - \\
\hline T1 child relationship with mother & - & $.23 * * *$ & - & $.23 * * *$ \\
\hline Father education level & .01 & .04 & -.01 & .03 \\
\hline Mother education level & -.05 & .00 & -.05 & .00 \\
\hline Couple income & -.04 & -.05 & -.03 & -.04 \\
\hline Child is female & -.01 & -.06 & -.01 & -.06 \\
\hline Child age & .01 & .04 & .00 & .04 \\
\hline Child is not white & -.04 & -.07 & -.04 & -.07 \\
\hline Intercept & $3.64 * * *$ & $2.53 *$ & $3.87 * * *$ & $2.62 * *$ \\
\hline$R^{2}$ & .13 & .11 & .13 & .12 \\
\hline
\end{tabular}

$* p<.05 . * * p<.01 . * * * p<.001 . n=254$; fit statistics for the Model 1 are the following: $\chi^{2}(473)=655.539, p<.001, \mathrm{CFI}=.952, \mathrm{RMSEA}=.039$, $\mathrm{SRMR}=.069$; Fit statistics for Model 2 not reported as they were unavailable due to the model being estimated using random slopes and intercepts so as to enable an interaction between the latent variables of combined parental psychological control psychological control and father/ mother materialism; all coefficients standardized 
time ( $B=-.29, \beta=-.19, p<.01$, Table 3) (i.e., even after controlling for the $\mathrm{T} 1$ father-child relationship). By way of contrast, mothers' materialism did not significantly predict mother-child relationship quality change $(B=.14, \beta=.08$, $p=.33)$.

\section{Hypothesis 2: Parental Psychological Control and Parent-Child Relationship Quality}

We confirmed hypothesis 2, that parental psychological control would be negatively associated with parent-child relationship quality. Time 1 combined parental psychological control predicted a decline in both father-child relationship quality $(B=-.49, \beta=-.21, p<.01)$ and mother-child relationship quality $(B=-.54, \beta=-.19, p<.01)$.

\section{Hypothesis 3: Parental Psychological Control as Moderator}

The results led us to reject Hypothesis 3, that parental psychological control will moderate the association between parental materialism and parent-child relationship quality. Neither the interaction of father materialism and combined parental psychological control nor mother materialism and combined parental psychological control significantly predicted father-child relationship quality or mother-child relationship quality.

\section{Parameter Difference Testing}

Following the structural models, we conducted a test assessing the difference between father materialism predicting father-child relationship quality and mother materialism predicting mother-child relationship quality. We did this to assess differences between father and mother materialism and the relationship it had with parent-child relationship quality. Using the Model Constraint command in Mplus, the difference between these parameters was calculated and was statistically significant $(\beta=-.25, p<.05)$ for Model 1 (the model without the interaction). This indicated that the association between father materialism and father-child relationship quality was statistically different (structurally not invariant) from the association between mother materialism and mother-child relationship quality. Of note, we tested this difference in Model 1 rather than Model 2 to eliminate any bias in our testing due to the non-significant effects of the interactions.

Following this test, we tested measurement invariance between mother and father measures of materialism using standard procedures (Meredith 1993; Widaman et al. 2010). The measures met the level for strict invariance indicating that our adapted materialism measure was qualitatively the same for fathers and mothers.

\section{Discussion}

Through the lens of self-determination theory (SDT), we investigated associations between parent-child relationship quality, materialism, and psychological control. We did this using longitudinal data that included reports from parents, children, and observers. A central contribution of this study is the notion that parental materialism plays a role in parent-child relationship quality. To our knowledge, this is the first major study to examine this relationship and to come to this conclusion. An additional contribution includes insight into self-determination theory. We discuss these contributions and other aspects of the study beginning with the role of parental materialism in parent-child relationships and lastly discuss implications for parents and practitioners.

\section{Materialism and Parent-Child Relationships}

The key contributions of the current study center on the apparent conflicting influences of fathers' and mothers' materialism on their relationships with their child. We found that higher levels of materialism for fathers at time one were associated with decreased father-child relationship quality at time two. This effect, though relatively small, was about the same magnitude as the lagged effect of time one parent-child relationship quality on time two parent-child relationship quality. This finding is consistent with Flouri's (2007) research suggesting that higher levels of father materialism are associated with negative parenting outcomes such as inter-parental conflict and parenting stress. In direct contrast, however, was the finding that higher levels of materialism for mothers were not significantly associated with mother-child relationship quality. We further found that the effect of father materialism on father-child relationship quality was statistically different from the effect of mother materialism on mother-child relationship quality, and that measures of materialism for mothers and materialism for fathers were invariant (qualitatively the same as each other) - emphasizing the validity of this difference.

Father materialism may be negatively related to their relationship with their child as a function of focusing on a provider role. More materialistic fathers may place extra emphasis on being a breadwinner and thus spend more time in that capacity. This in turn takes away from time spent with children and subsequently worsens father-child relationship quality. Past work supports this idea as researchers have found that many contemporary fathers still view financial earning as a core feature of their fathering role (Kuo et al. 2018), and the endorsement of 
more traditional masculine norms is linked with decreased father engagement and warmth (Petts et al. 2018). Future work can explore if father perceptions of provider roles and masculine norms indeed mediate the relationship between materialism and parent-child relationship quality.

At first glance, this explanation should apply to mothers. If materialism is harmful to father-child relationships (as a function of focusing on the provider role), mothers with a similar focus should also have worsened parent-child relationships. However, providing mothers may differ from providing fathers in that they give up time in other domains (e.g., leisure time, household labor) to maintain the amount of time they would spend with children if they were not employed (Huston and Aronson 2005). Huston and Aronson (2005) found that maternal time use was correlated with maternal sensitivity and with the quality of the home environment. They also found that maternal employment was correlated with the quality of the home environment. Both maternal sensitivity and the quality of the home environment are well-known correlates of positive infant and child outcomes (for review, see Deans 2018). Subsequently, materialistic mothers who intentionally compensate for time at work by reducing time in other activities, or materialistic mothers whose income is used to improve the quality of the home environment for their children would likely not experience declines in parent-child relationship quality.

We explored this explanation further in a post hoc analysis $(n=192)$ which included the same variables as those in Table 3, model 2, and additionally, controlled for Time 1 father and mother work hours. Specifically, we regressed father work hours on Time 2 father-child relationship quality and regressed mother work hours on Time 2 mother-child relationship quality. The post hoc model and model 2 from Table 3 were identical except for these added controls and an additional constraint (constraining the variances of the latent mother and father couple psychological variables to be the same to avoid having a negative residual variance). Of note, mother materialism still was not significantly associated with mother-child relationship quality $(\beta<.01$, $p=.99)$. Also, father materialism was still negatively and significantly associated with father-child relationship quality at trend levels $(\beta=-.16, p=.08)$. The results of this post hoc analysis provide further evidence that mother time spent working as well as mother materialism do not harm mother-child relationships. All results of this analysis are available upon request.

Why then is materialism apparently harmful for father and child relations but not harmful for mothers and children? This appears to be a complex finding that requires continued research. However, one explanation is that mother materialism is not related to their relationship with their child due to a link between materialism and empowerment. Leavitt et al. (2019) suggested "women may be deriving some sense of empowerment from... materialism" (p. 449) as one explanation for their finding that women's materialism related to higher men's satisfaction within their relationship. Similarly, empowerment of mothers through materialism may buffer the otherwise potentially negative effects materialism may have on mother-child bonds.

In line with previous literature (Pahl 1995; Yodanis and Lauer 2007), another explanation for this mother-father difference is that mothers may be more likely to spend for the benefit of children as compared to fathers. Extra income in the hands of women in microfinancing situations has been found to improve children's welfare greater than when it is in the hands of men (e.g., Engle 1993; Thomas 1990). By extension, additional spending on behalf of children by materialistic mothers may cancel out any potential harmful effects of mother materialism on maternal bonds. Importantly, we recognize that extracting results from microfinance situations in unaffluent samples to provide explanations for materialistic motivations in an affluent sample may not be equitable. Therefore, we advise being judicious in applying these explanations.

Overall, one implication from the conflicting influences of materialism on parent-child relationships (i.e., for mothers it appears to have no effect but for fathers it seems to be harmful) is that materialism cannot be categorized as only positive or only negative, good or bad. We recommend further investigation of the motivations and processes behind materialistic attitudes and the acquisition of goods.

\section{Psychological Control and Parent-Child Relationships}

The current study also identified negative associations between parental psychological control and father and mother relationships with their child. Specifically, we found that higher levels of combined parental psychological control at time one were associated with decreased mother and father-child relationship quality at time two. These effects were about the same magnitude as the lagged effect of time one parent-child relationship quality on time two parent-child relationship quality. This finding is in line with prior research suggesting that psychological control is negatively linked with parent child relationships (Barber 1996; Holmes et al. 2013; Smetana and Daddis 2002). Because psychological control includes manipulation and invalidation, these behaviors are also often linked with negative child and adolescent outcomes (Barber et al. 2005; Doyle and Markiewicz 2005; Wang et al. 2007), thus these findings have clear implications for both relationship quality as well as child and adolescent development in families where psychological control is prevalent. 


\section{Implications for Self-determination Theory}

Based on the conflicting influence of parental materialism on parent-child relationships, we suggest our study only partially supports tenets of SDT. External motivations as represented through materialism did not unequivocally relate to poorer relational quality as SDT would suggest. External materialistic motivation was seemingly benign for mother-child relations but deleterious for father-child bonds. It may be that materialistic attitudes fall outside the scope of SDT, and other theories for addressing materialism in parent-child relations may be more appropriate. Future work can integrate other theory or develop new frameworks to investigate this connection.

\section{Implications for Parents and Practitioners}

Our results have implications for parents and practitioners, such as financial therapists, who endeavor to find balance between materialistic goals and relationships with children. Parents, especially parents struggling to have positive relationships with their children, may benefit from considering how materialistic ambitions are affecting relations with their children. This self-examination may lead to corrections in priorities or improvement in work-family balance that in turn promote stronger parent-child bonds. Family life specialists and marriage and family therapists can aid parents by promoting this type of self-exploration in educational and therapeutic settings to promote better bonds with children, especially with adolescents. Although not yet replicated, based on our results we suggest that fathers-who appear to be most at risk for poorer parent-child relations due to materialism-especially may benefit from this type of selfexamination. In summary, it may be fruitful for parents to determine how materialism is or is not affecting relationships with their children and adjust where necessary.

\section{Limitations}

Several limits exist in the current study. First, the sample was affluent and primarily white. Therefore, findings may not extend readily to less affluent groups or other race/ethnic groups. Further, we note that the amount of variance explained in relationship quality variables is limited and that, while statistically significant, key relationships between materialism predictors and relationship outcomes only met minimum levels of significance $(p<.05$ as compared to $p<.01$ or $p<.001$ ). Lastly, we note that data were taken from one major city in the northwestern United States and thus generalizability is limited due to regional differences in parenting behaviors across the U.S. Accordingly, findings should be confirmed in future investigations and cautiously applied in policy and therapeutic settings.

\section{Conclusion}

Materialism in the context of parent-child relationships is complex. This study provides insight and further questions regarding the role materialism plays in the bond between parent and child. This study also serves as a springboard for future work. We believe additional insight into how parents and children may better connect will result as researchers perform necessary added investigation.

Funding The data utilized in the current study was funding by donors and funding agencies including the School of Family Life Endowment (BYU), Family Studies Center Endowment (BYU), Marjorie Pay Hinckley Endowed Chair (BYU), Mary Lou Fulton Endowed Chair in the Social Sciences (BYU), Mentoring Environment Grant (BYU), LB and LW Smith and Family Foundation, Kreutzkamp Family Foundation, Brent and Cheri Andrus Family Trust, and James W. and Carolyn O. Ritchie Supporting Organization.

\section{Compliance with Ethical Standards}

Conflict of interest The authors declare that they have no conflict of interest.

Ethical Approval This article does not contain any studies with human participants performed by any of the authors.

Informed Consent Informed consent was obtained from all individual participants included in the study.

\section{References}

Barber, B. (1996). Parental psychological control: Revisiting a neglected construct. Child Development, 67, 3296-3319.

Barber, B. K., Stolz, H. E., \& Olsen, J. A. (2005). Parental support, psychological control, and behavioral control: Assessing relevance across time, culture, and method. Monographs of the Society for Research in Child Development, 282(70), 1-137.

Belk, R. W. (1984). Three scales to measure constructs related to materialism: Reliability, validity, and relationships to measures of happiness. ACR North American Advances.

Burroughs, J. E., \& Rindfleisch, A. (2002). Materialism and wellbeing: A conflicting values perspective. Journal of Consumer research, 29, 348-370.

Carroll, J. S. (2004). The Comprehensive Marriage Preparation Asessment Survey (COMPASS). (C) TM Springville, UT: Persona LLC. [copyrighted and patent pending].

Carroll, J. S., Dean, L. R., Call, L. L., \& Busby, D. M. (2011). Materialism and marriage: Couple profiles of congruent and incongruent spouses. Journal of Couple \& Relationship Therapy, 10, 287-308.

Chakraborty, E., \& Chatterjee, I. (2015). Relation between materialistic value, spiritual oneness belief and physical oneness belief 
with happiness: A study on young professionals. Indian Journal of Positive Psychology, 6(3), 245.

Christopher, A. N., \& Schlenker, B. R. (2004). Materialism and affect: The role of self-presentational concerns. Journal of Social and Clinical Psychology, 23, 260-272.

Day, R. D., Coyne, S., Dyer, J., Harper, J., \& Walker, L. (2016). Flourishing families project: survey of family life.

Dean, L. R., Carroll, J. S., \& Yang, C. (2007). Materialism, perceived financial problems, and marital satisfaction. Family and Consumer Sciences Research Journal, 35, 260-281.

Deans, C. L. (2018). Maternal sensitivity, its relationship with child outcomes, and interventions that address it: A systematic literature review. Early Child Development and Care. https://doi. org/10.1080/03004430.2018.1465415.

Deci, E. L., \& Ryan, R. M. (1980). Self-determination theory: When mind mediates behavior. The Journal of Mind and Behavior, 1(1), 33-43.

Deci, E. L., \& Ryan, R. M. (2000). The "what" and "why" of goal pursuits: Human needs and the self-determination of behavior. Psychological Inquiry, 11(4), 227-268.

Doyle, A. B., \& Markiewicz, D. (2005). Parenting, marital conflict and adjustment from early- to mid-adolescence: Mediated by adolescent attachment style? Journal of Youth and Adolescence, 34, 97-110.

Easterlin, R. A., \& Crimmins, E. M. (1991). Private materialism, personal self-fulfillment, family life, and public interest: The nature, effects, and causes of recent changes in the values of American youth. Public Opinion Quarterly, 55, 499-533.

Engle, P. L. (1993). Influences of mothers' and fathers' income on children's nutritional status in Guatemala. Social Science \& Medicine, 37(11), 1303-1312.

Flouri, E. (2004). Exploring the relationship between mothers' and fathers' parenting practices and children's materialist values. Journal of Economic Psychology, 25(6), 743-752.

Flouri, E. (2007). The relationship between parenting and materialism in British mothers and fathers of secondary school age children. The Journal of Socio-Economics, 36, 167-176.

Holmes, E. K., Dunn, K. C., Harper, J. M., Dyer, W. J., \& Day, R. D. (2013). Mother knows best? Inhibitory maternal gatekeeping, psychological control, and the mother-adolescent relationship. Journal of Adolescence, 36, 91-101. https://doi.org/10.1016/j. adolescence.2012.09.010.

Huston, A. C., \& Aronson, S. R. (2005). Mothers' time with infant and time in employment as predictors of mother-child relationships and children's early development. Child Development, 76(2), 467-482.

IBM Corp. (2017). IBM SPSS Statistics for Windows, Version 25.0. Armonk, NY: IBM Corp.

Jiang, J., Zhang, Y., Ke, Y., Hawk, S. T., \& Qiu, H. (2015). Can't buy me friendship? Peer rejection and adolescent materialism: Implicit self-esteem as a mediator. Journal of Experimental Social Psychology, 58, 48-55.

Kashdan, T. B., \& Breen, W. E. (2007). Materialism and diminished well-being: Experiential avoidance as a mediating mechanism. Journal of Social and Clinical Psychology, 26(5), 521-539.

Kasser, T. (2002). The high price of materialism. Cambridge, MA: The MIT Press.

Kasser, T., \& Ryan, R. M. (1993). A dark side of the American dream: Correlates of financial success as a central life aspiration. Journal of Personality and Social Psychology, 65(2), 410-422.

Kasser, T., \& Ryan, R. M. (1996). Further examining the American dream: Differential correlates of intrinsic and extrinsic goals. Personality and Social Psychology Bulletin, 22(3), 280-287.

Kasser, T., \& Ryan, R. M. (2001). Be careful what you wish for: Optimal functioning and the relative attainment of intrinsic and extrinsic goals. In P. Schmuck \& K. M. Sheldon (Eds.), Life goals and well-being: Towards a positive psychology of human striving (pp. 280-287). Ashland, OH: Hogrefe \& Huber Publishers.

Kuo, P. X., Volling, B. L., \& Gonzalez, R. (2018). Gender role beliefs, work-family conflict, and father involvement after the birth of a second child. Psychology of Men \& Masculinity, 19(2), 243-256.

Leavitt, C. E., Dew, J. P., Allsop, D. B., Runyan, S. D., \& Hill, E. J. (2019). Relational and sexual costs of materialism in couple relationships: An actor-partner longitudinal study. Journal of Family and Economic Issues, 40, 438-454.

Li, N. P., Patel, L., Balliet, D., Tov, W., \& Scollon, C. N. (2011). The incompatibility of materialism and the desire for children: Psychological insights into the fertility discrepancy among modern countries. Social Indicators Research, 101(3), 391-404.

Melby, J., Conger, R., Book, R., Rueter, M., Lucy, L., Repinski, D., et al. (1998). The Iowa family interaction rating scales. Ames: Iowa State University. Institute for Social and Behavioral Research.

Meredith, W. (1993). Measurement invariance, factor analysis and factorial invariance. Psychometrika, 58(4), 525-543.

Muthén, L.K. and Muthén, B.O. (1998-2017). Mplus User's Guide. Eighth Edition. Los Angeles, CA: Muthén \& Muthén

Pahl, J. (1995). His money, her money: Recent research on financial organisation in marriage. Journal of Economic Psychology, 16(3), 361-376. https://doi.org/10.1016/0167-4870(95)00015-G.

Petts, R. J., Shafer, K. M., \& Essig, L. (2018). Does adherence to masculine norms shape fathering behavior? Journal of Marriage and Family, 80(3), 704-720.

Promislo, M. D., Deckop, J. R., Giacalone, R. A., \& Jurkiewicz, C. L. (2010). Valuing money more than people: The effects of materialism on work-family conflict. Journal of Occupational and Organizational Psychology, 83, 935-953.

Richins, M. L. (2004). The material values scale: Measurement properties and development of a short form. Journal of Consumer Research, 31(1), 209-219.

Richins, M. L., \& Dawson, S. (1992). A consumer values orientation for materialism and its measurement: Scale development and validation. Journal of Consumer Research, 19, 303-316.

Roberts, J. A., \& Clement, A. (2007). Materialism and satisfaction with over-all quality of life and eight life domains. Social Indicators Research, 82(1), 79-92.

Ryan, L., \& Dziurawiec, S. (2001). Materialism and its relationship to life satisfaction. Social Indicators Research, 55(2), 185-197.

Ryan, R. M., \& Deci, E. L. (2002). Overview of self-determination theory: An organismic dialectical perspective. In E. L. Deci \& R. M. Ryan (Eds.), Handbook of self-determination research (pp. 3-33). Rochester, NY: University of Rochester Press.

Shrum, L. J., Lowrey, T. M., Pandelaere, M., Ruvio, A. A., Gentina, E., Furchheim, P., et al. (2014). Materialism: The good, the bad, and the ugly. Journal of Marketing Management, 30, 1858-1881.

Sirgy, M. J. (1998). Materialism and quality of life. Social Indicators Research, 43(3), 227-260.

Sirgy, M. J., Gurel-Atay, E., Webb, D., Cicic, M., Husic-Mehmedovic, M., Ekici, A., et al. (2013). Is materialism all that bad? Effects on satisfaction with material life, life satisfaction, and economic motivation. Social Indicators Research, 110, 349-366.

Smetana, J. G., \& Daddis, C. (2002). Domain-specific antecedents of parental psychological control and monitoring: The role of parenting beliefs and practices. Child Development, 73(2), 563-580.

Thomas, D. (1990). Intra-household resource allocation: An inferential approach. Journal of Human Resources, 25(4), 635-664.

Wang, Q., Pomerantz, E. M., \& Chen, H. (2007). The role of parents' control in early adolescents' psychological functioning: A longitudinal investigation in the United States and China. Child Development, 78(5), 1592-1610.

Widaman, K. F., Ferrer, E., \& Conger, R. D. (2010). Factorial invariance within longitudinal structural equation models: Measuring 
the same construct across time. Child Development Perspectives, 4(1), 10-18.

Yodanis, C., \& Lauer, S. (2007). Managing money in marriage: Multilevel and cross-national effects of the breadwinner role. Journal of Marriage and Family, 69(5), 1307-1325. https://doi.org/10.11 11/j.1741-3737.2007.00449.x.

Publisher's Note Springer Nature remains neutral with regard to jurisdictional claims in published maps and institutional affiliations.

David B. Allsop is a doctoral student in psychology and neuroscience at Dalhousie University. His research focuses on healthy sexual relationships in long-term committed relationships over the life course, primarily in terms of how couples have healthy and satisfying sexual relationships during times of heightened stress, as well as other factors that affect families such as materialism. He received his master's degree in marriage, family, and human development from Brigham Young University in 2020.

Chen-Yun Wang is a researcher at The Church of Jesus Christ of Latterday Saints. In her scholarly work, she has focused on parenting and child outcomes in crosscultural contexts. She received her master's degree in marriage, family, and human development from Brigham Young University in 2019.

Jeffrey P. Dew is an Associate Professor in the School of Family Life at Brigham Young University. He teaches family theory and family finance courses at BYU. His research focuses on the "daily life" issue of the association between family resources (i.e., money and time) and relationship quality. Examples of his recent projects include examining factors that protect couples' marital quality during financial difficulties, and a qualitative strengths-based analysis of how African American couples talk about the role of finances in their marriage.

Erin K. Holmes is an Associate Professor in the School of Family Life at Brigham Young University. Her research focuses on fathering, mothering, and the work-family interface. She earned her Ph.D. in Human Development and Family Sciences from The University of Texas at Austin.

E. Jeffrey Hill is Professor and Associate Director of the School of Family Life at Brigham Young University where he teaches classes in family finance to about 1000 students each year. His research examines the interface of finances and family life. He obtained a doctorate in Family and Human Development at Utah State University and Masters of Organizational Behavior from the Marriott School of Management at Brigham Young University. He has authored or co-authored seven books and more than 100 scholarly articles and book chapters. $\mathrm{He}$ and his wife Tammy are blending a family of 12 children and 33 grandchildren.

Chelom E. Leavitt is an Assistant Professor in The School of Family Life at Brigham Young University. In her scholarly work, she examines how mindfulness, sexual mindfulness, and other variables are connected to individuals' and couples' relational and sexual well-being, as well as how constructs such as materialism are associated with relationship quality for romantic dyads. She earned her Ph.D. in Human Development and Family Sciences from Penn State. 